\title{
Protection of Iron-Induced Oxidative Damage in Neuroblastoma (SH-SY5Y) Cells by Combination of 1-(N-Acetyl-6-aminohexyl)-3-hydroxy-2-methylpyridin-4-one and Green Tea Extract
}

\author{
Nittaya Chansiw, ${ }^{1}$ Kanokwan Kulprachakarn, ${ }^{2}$ Narisara Paradee, ${ }^{3}$ Adchara Prommaban, ${ }^{3}$ \\ and Somdet Srichairatanakool $\mathbb{D i}^{3}$ \\ ${ }^{1}$ School of Medicine, Mae Fah Luang University, Chiang Rai 57100, Thailand \\ ${ }^{2}$ Research Institute for Health Science, Chiang Mai University, Chiang Mai 50200, Thailand \\ ${ }^{3}$ Oxidative Stress Cluster, Department of Biochemistry, Faculty of Medicine, Chiang Mai University, Chiang Mai 50200, Thailand \\ Correspondence should be addressed to Somdet Srichairatanakool; somdet.s@cmu.ac.th
}

Received 20 February 2021; Accepted 11 April 2021; Published 20 April 2021

Academic Editor: Franc Perdih

Copyright (c) 2021 Nittaya Chansiw et al. This is an open access article distributed under the Creative Commons Attribution License, which permits unrestricted use, distribution, and reproduction in any medium, provided the original work is properly cited.

\begin{abstract}
Iron is a crucial trace element and essential for many cellular processes; however, excessive iron accumulation can induce oxidative stress and cell damage. Neurodegenerative disorders, such as Alzheimer's disease and Parkinson's disease, have been associated with altered iron homoeostasis causing altered iron distribution and accumulation in brain tissue. This study aims to investigate the protective effect of 1-(N-acetyl-6-aminohexyl)-3-hydroxy-2-methylpyridin-4-one (CM1) in combination with green tea extract (GTE) on iron-induced oxidative stress in neuroblastoma (SH-SY5Y) cells. Cells were cultured in medium with or without ferric chloride loading. Their viability and mitochondrial activity were assessed using MTT and JC-1 staining methods. Levels of the cellular labile iron pool (LIP), reactive oxygen species (ROS), and lipidperoxidation products were determined using calcein acetoxymethyl ester, $2^{\prime}, 7^{\prime}$-dichlorohydrofluorescein diacetate, and TBARS-based assays, respectively. The viability of iron-loaded cells was found to be significantly increased after treatment with CM1 $(10 \mu \mathrm{M})$ for $24 \mathrm{~h}$. CM1 co-treatment with GTE resulted in a greater protective effect than their monotherapy. Combination of CM1 and GTE also reduced mitochondrial disruption and LIP content and ROS and TBARS production. In conclusion, the combination of CM1 and GTE exhibits protection against iron-induced oxidative stress in neuroblastoma cells.
\end{abstract}

\section{Introduction}

Iron is an essential element which is involved in many cellular processes including oxygen transport, oxygen sensing, electron transduction, energy metabolism, and DNA synthesis. However, it also participates in the undesirable Fenton reaction by reacting with hydrogen peroxide to generate the hydroxyl radical and other reactive oxygen species (ROS) $[1,2]$. ROS attacks polyunsaturated fatty acids, causing peroxidation, which in turn causes disorganization and dysfunction $[3,4]$. Lipid peroxidation is used as an indicator of oxidative stress in cells and tissues and can be monitored by the formation of byproducts such as malondialdehyde (MDA). Normally, iron is efficiently taken up by cells using the divalent metal transporter 1 , this process being tightly controlled. However, an abnormally high iron uptake will increase the cellular labile iron pool (LIP), which could then lead to oxidative damage and cell death $[1,5]$. During the natural process of aging, different iron complexes accumulate in brain regions that cause motor and cognitive impairment $[4,6,7]$. Neurodegenerative diseases, such as Alzheimer's disease and Parkinson's 
disease, are associated with a change in iron homoeostasis resulting in altered cellular iron distribution and accumulation [8-10].

Interestingly, iron chelators, such as 7,8-dihydroxy-4((methylamino)methyl)-2H-chromen-2-one, dihydroxamat e peptide and deferiprone (DFP), are effective in removing excess intracellular iron pools, thereby inhibiting lipid peroxidation and maintaining the normal mitochondrial membrane potential of neuronal cells [11-13]. Such chelators have potential to provide neuroprotection in neurodegenerating disease $[12,13]$. Tea extracts have been separated to attenuate 6-hydroxydopamine-induced neuroblastoma (SH-SY5Y) cell death via the anti-oxidant and iron-chelating properties of polyphenols, particularly epigallocatechin-3-gallate (EGCG) $[14,15]$.

1-(N-Acetyl-6-aminohexyl)-3-hydroxypyridin-4-one (CM1) is an orally active bidentate iron chelator firstly synthesized by Pangjit et al. [16]. It is a DFP analogue but is characterized by a higher level of lipid solubility [17]. In a previous study, CM1 was demonstrated to effectively bind iron under biological conditions. It also reduces plasma nontransferrin bound iron and labile plasma iron [18]. Importantly, the compound shows low toxicity $[19,20]$. However, there are published reports of this compound processing a neuroprotective effect. Green tea extract (GTE) prepared from tea (Camellia sinensis) leaves is predominantly comprised of polyphenolic catechins, of which EGCG is the most abundant $[21,22]$. Interestingly, EGCG has been reported to protect AS-PC12 and SH-SY5Y cells against iron-induced oxidative stress [23, 24]. Likewise, we have previously demonstrated that GTE exhibits anti-oxidant, free radical-scavenging, and iron chelating activities in ironloaded thalassemia mice [25]. In the present study, we reported the protective effect of CM1 in combination with GTE against iron-induced oxidative stress in SH-SY5Y cells.

\section{Materials and Methods}

2.1. Chemicals and Reagents. Calcein acetoxymethyl (CA-AM) and JC-1 dye were purchased from Invitrogen ${ }^{\circledR}$ Corporation (Carlsbad, CA, USA). Furthermore, $2^{\prime}, 7^{\prime}$-dich lorodihydrofluorescein diacetate (DCFH-DA), dimethyl sulfoxide (DMSO), epigallocatechin-3-gallate (EGCG), ferric chloride $\left(\mathrm{FeCl}_{3}\right)$, 1,1,3,3-tetramethoxypropane (TMP), thiobarbituric acid (TBA), $\alpha$-tocopherol (TC), thiobarbituric acid (TBA), and 3-(4,5-dimethyl-2-thiazolyl)-2,5-diphenyl-2- $\mathrm{H}$-t etrazolium bromide (MTT) were purchased from Sigma-Al drich Chemicals Company (St. Louis, MO, USA). Bradford's reagent was purchased from Bio-Rad Laboratories, Inc. (Hercules, CA, USA). Dulbecco's Modified Eagle Medium (DMEM), Ham's F12 Nutrient Mixture, fetal bovine serum (FBS), phosphate-buffered saline (PBS) $\mathrm{pH} 7.0$, and penic illin-streptomycin were purchased from Gibco Laboratories (Gaithersburg, MD, USA).

2.2. Substances. CM1 was synthesized according to literature procedure [17]. GTE was locally prepared from fresh tea (Camellia sinensis) leaves using a microwave-based method to dry the leaves and for the inactivation of polyphenol oxidase. Subsequently, EGCG was found to be $24 \%(w / w)$ of the final product [16]. GTE was freshly dissolved in 1\% (v/v) DMSO each day and concentrations were expressed as $\mathrm{mg} /$ $\mathrm{mL}$ and EGCG equivalents. Among iron sources, $\mathrm{FeCl}_{3}$ and $\mathrm{FeCl}_{2}$ were used as a redox iron for loading into cells to induce iron overload [26-28]. In this study, the iron solution $(100 \mathrm{mM})$ was initially prepared by dissolving $16.22 \mathrm{mg}$ of $\mathrm{FeCl}_{3}$ in $1.0 \mathrm{~mL}$ of $500 \mathrm{mM}$ citric acid and diluted in working medium to achieve the final concentration of $2 \mathrm{mM}$.

2.3. Cell Culture. Human neuroblastoma (SH-SY5Y) cell line was purchased from the American Type Culture Collection (ATCC ${ }^{\circledR}$ CRL2266 $^{\mathrm{TM}}$, Manassas, VA, USA). Cells were cultured in DMEM and Ham's F12 Nutrient Mixture (a ratio of $1: 1, \mathrm{v} / \mathrm{v})$ supplemented with $20 \%(\mathrm{v} / \mathrm{v})$ FBS, $100 \mathrm{U} /$ $\mathrm{mL}$ penicillin, and $100 \mu \mathrm{g} / \mathrm{mL}$ streptomycin. Cells were then maintained at $37^{\circ} \mathrm{C}$ in a $5 \% \mathrm{CO}_{2}$ incubator.

2.4. Cell Toxicity Study. The toxic effects of CM1 and GTE were investigated by measuring the viability of SH-SY5Y cells using the MTT assay [29]. Briefly, SH-SY5Y cells $\left(2 \times 10^{4} /\right.$ well $)$ were seeded onto 96 -well plates and left for $24 \mathrm{~h}$. The cells were then treated with $1 \%$ DMSO (control), CM1 $(10-100 \mu \mathrm{M})$, and GTE $(10-100 \mathrm{mg} / \mathrm{mL}$ equivalent to 5.24-52.4 $\mu \mathrm{M}$ EGCG, respectively) for 24 or $48 \mathrm{~h}$. Then, a MTT solution $(5 \mathrm{mg} / \mathrm{mL})$ was added to the cells and they were incubated for a further $4 \mathrm{~h}$ at $37^{\circ} \mathrm{C}$. The medium was removed and 1\% DMSO solution was added to the well plates in order to dissolve the formazan crystals. The optical density (OD) was measured at a wavelength of $540 \mathrm{~nm} /$ $630 \mathrm{~nm}$ using a 96-well microtiter plate reader (BioTek Synergy H4 Hybrid Reader, BioTek Instruments Inc., VT, USA). Untreated cells were used as a control group.

Under iron-overload conditions, SH-SY5Y cells $\left(2 \times 10^{4} /\right.$ well) were seeded onto 96-well plates for $24 \mathrm{~h}$. They were incubated in medium containing $2 \mathrm{mM} \mathrm{FeCl}_{3}$ for $24 \mathrm{~h}$ and then washed three times with PBS pH 7.0. The cells were then treated with CM1 and GTE at the indicated concentrations and 1\% DMSO (control) for $24 \mathrm{~h}$. Finally, cell viability of the treated cells was estimated using the MTT assay as described above.

2.5. Measurement of Mitochondrial Membrane Potential. Disruption of mitochondrial membrane potential (MMP, $\left.\Delta \Psi_{\mathrm{m}}\right)$ is one of the intracellular events leading to apoptosis. The $5,5^{\prime}, 6,6^{\prime}$-tetrachloro-1,1',3,3'-tetraethylbenzimidazolyl carbo-cyanine iodide (JC-1) dye, which is a lipophilic cationic carbocyanine fluorescent probe used to identify changes in the MMP, selectively enters into the mitochondria and reversibly changes color from green to red as the MMP changes. In healthy cells with a high MMP level, JC-1 spontaneously forms complexes with an intense red fluorescence. In contrast, with apoptotic or unhealthy cells with low MMP, JC-1 remains in the monomeric form and displays only green fluorescence. SH-SY5Y cells $\left(5 \times 10^{4}\right.$ / well) were seeded onto a 24 -well plate for $24 \mathrm{~h}$, the medium 
was removed, and the cells were loaded with the $2 \mathrm{mM} \mathrm{FeCl}_{3}$. After $24 \mathrm{~h}$, the medium was removed and the cells were washed two times with PBS. The cells were then treated with $1 \%$ DMSO (control), CM1 (10, 20, and $40 \mu \mathrm{M})$, GTE $(10,20$, and $40 \mathrm{mg} / \mathrm{mL}$ equivalent to $5.24,10.48$, and $20.96 \mu \mathrm{M}$ EGCG, respectively), and combinations of CM1 and GTE for $24 \mathrm{~h}$. After discarding the medium, the treated cells were washed two times with PBS, and JC-1 dye was added and incubated in the dark at $37^{\circ} \mathrm{C}$ for $20 \mathrm{~min}$. After this short incubation, fluorescence intensity (FI) at an excitation wavelength of $510 \mathrm{~nm}$ and an emission wavelength of $527 \mathrm{~nm}$ was recorded by flow cytometry (DxFLEX Flow Cytometer, Beckman Coulter Life Sciences, IN, USA) [30]. The resulting FI was a measure of the percentage change of MMP.

2.6. Measurement of Labile Iron Pool. The level of the intracellular labile iron pool (LIP) was investigated using the fluorescence calcein quenching technique [31]. In principle, CA-AM passes through the cell membrane and reacts with cytosolic unspecific esterases to produce calcein, a hydrophilic fluorochrome which is retained within the cytosol of the cells. Calcein fluorescence is quenched in the presence of labile iron, the degree of quenching providing an estimate of the amount of chelatable iron present in the cytosol. Briefly, SH-SY5Y cells $\left(1 \times 10^{4} /\right.$ well $)$ were seeded onto a black 96well plate for $24 \mathrm{~h}$, and the medium was replaced with the medium containing $2 \mathrm{mM} \mathrm{FeCl}_{3}$. After incubation for $24 \mathrm{~h}$, the medium was removed and the cells were washed three times with PBS. The cells were then treated with $1 \%$ DMSO, different concentrations of CM1 $(10,20$, and $40 \mu \mathrm{M})$, EGCG $(10,20$, and $40 \mu \mathrm{M})$, GTE $(10,20$, and $40 \mathrm{mg} / \mathrm{mL}$ equivalent to $5.24,10.48$, and $20.96 \mu \mathrm{M}$ EGCG, respectively), and combinations of the EGCG and GTE with $10 \mu \mathrm{M}$ CM1 for $24 \mathrm{~h}$. After discarding the medium, the treated cells were washed with PBS two times, and CA-AM $(1 \mu \mathrm{M}$ in PBS) was added and incubated for $30 \mathrm{~min}$ at $37^{\circ} \mathrm{C}$. After calcein loading, the cells were washed three times with PBS and FI measured at an excitation wavelength of $488 \mathrm{~nm}$ and an emission wavelength of $515 \mathrm{~nm}$. The cells without iron loading were used as a control group $(100 \% \mathrm{FI})$ to calculate the percentage change of FI after the various treatments.

2.7. Analysis of Reactive Oxygen Species. ROS production was investigated using DCFH-DA staining and then anal yzed by spectrofluorometric analysis [32]. DCFH-DA diffuses into the cells and is hydrolyzed by cellular esterase to produce $2^{\prime}, 7^{\prime}$-dichlorofluorescein (reduced form), which will then be subsequently oxidized by existing ROS to a green-fluorescence $2^{\prime}, 7^{\prime}$-dichlorofluorescein (DCF) produ ct. Notably, high green FI indicates a high level of int racellular ROS. SH-SY5Y cells $\left(2 \times 10^{4} /\right.$ well $)$ were seeded onto a 96-well plate for $24 \mathrm{~h}$, then the medium was rem oved, and the cells were loaded with the medium cont aining $2 \mathrm{mM} \mathrm{FeCl}_{3}(24 \mathrm{~h})$. The cells were then incubated with $1 \%$ DMSO (control), $\alpha$-tocopherol $(0.46 \mu \mathrm{M})$, different concentrations of CM1 and GTE, and combinations of the two for $24 \mathrm{~h}$ at $37^{\circ} \mathrm{C}$. The cells were then treated with
DCFH-DA solution $(10 \mu \mathrm{M})$ at $37^{\circ} \mathrm{C}$ for $30 \mathrm{~min}$. The cells were washed twice with PBS solution and FI was measured at an excitation wavelength of $485 \mathrm{~nm}$ and an emission wavelength of $530 \mathrm{~nm}$ using a 96-well plate spectrofluorometer (BioTek Synergy H4 Hybrid Reader, BioTek Instruments Inc., VT, USA) for $1 \mathrm{~h}$ to establish kinetic measurement. The FI value is directly proportional to the amount of ROS present in the cells. The iron-loaded cells treated with 1\% DMSO were used as a control group (100\% FI) to calculate the percentage change of FI after the various treatments.

2.8. Quantification of Lipid-Peroxidation Products. TBA reacts with aldehydes that are released from the lipid peroxidation of membrane phospholipids to yield a pink-colored product which can be determined photometrically. SH-SY5Y cells $\left(1.5 \times 10^{6} /\right.$ well $)$ were seeded onto a 6 -well plate for $24 \mathrm{~h}$ and then iron-loaded for further $24 \mathrm{~h}$. The cells were then incubated with $1 \%$ DMSO (control), $\alpha$-tocopherol $(0.46 \mu \mathrm{M})$, different concentrations of CM1 and GTE, and combinations of the two for $24 \mathrm{~h}$ at $37^{\circ} \mathrm{C}$. The treated cells were harvested, washed with PBS twice, and centrifuged at $300 \mathrm{~g}$ for $10 \mathrm{~min}$. The cell pellets were collected and resuspended in PBS. Cell lysates were prepared by placing cells in a Bioruptor water bath sonicator (the condition set at $24 \mathrm{sec} \mathrm{ON}, 24 \mathrm{sec}$ OFF) housed in a cold room $\left(5-6^{\circ} \mathrm{C}\right)$ for $2-3 \mathrm{~min}$ and centrifuged at $10,000 \mathrm{~g}$ for $15 \mathrm{~min}$. Total protein content was determined using Bradford's reagent. The lipid-peroxidation products were measured colorimetrically using the TBARS assay. Cell lysate or standard MDA was mixed with $1 \%$ meta-phosphoric acid and $0.67 \% \mathrm{TBA}$ and incubated in a water bath at $95^{\circ} \mathrm{C}$ for 60 min. After being cooled, $n$-butanol was added and the mixtures were centrifuged at $4500 \mathrm{rpm}$ for $5 \mathrm{~min}$. The OD of the $n$-butanol phase was measured at $535 \mathrm{~nm}$ using a double beam UV-VIS spectrophotometer. Standard curves were prepared over the concentration range $0.312-20 \mu \mathrm{M}$ TMP.

2.9. Statistical Analysis. The results were expressed as mean \pm standard error of the mean (SEM) of three independent measurements. Statistical analysis was determined using one-way analysis of variance (ANOVA), after which a post-hoc test was applied. Values of $P<0.05$ were considered to be significantly different.

\section{Results}

3.1. Toxicity on SH-SY5YCells. Cell viability was significantly increased in a concentration-dependent manner when SHSY5Y cells were treated with CM1 for $24 \mathrm{~h}$, in which 10 and $20 \mu \mathrm{M}$ CM1 treatments improved the viability of iron-loaded cells, while 80 and $100 \mu \mathrm{M} \mathrm{CM} 1$ were found to be toxic to the cells and decreased the degree of viability significantly (Figure 1(a)). In comparison, all GTE concentrations were found to be non-toxic to normal neuroblastoma cells (cell viability $>90 \%$ ) (Figure 1(b)). Similarly, GTE in the range of $10-80 \mathrm{mg} / \mathrm{mL}(5.2-41.9 \mu \mathrm{M}$ EGCG equivalent) improved viability of the iron-loaded cells. However, the degree of cell viability was decreased in a concentration-dependent 


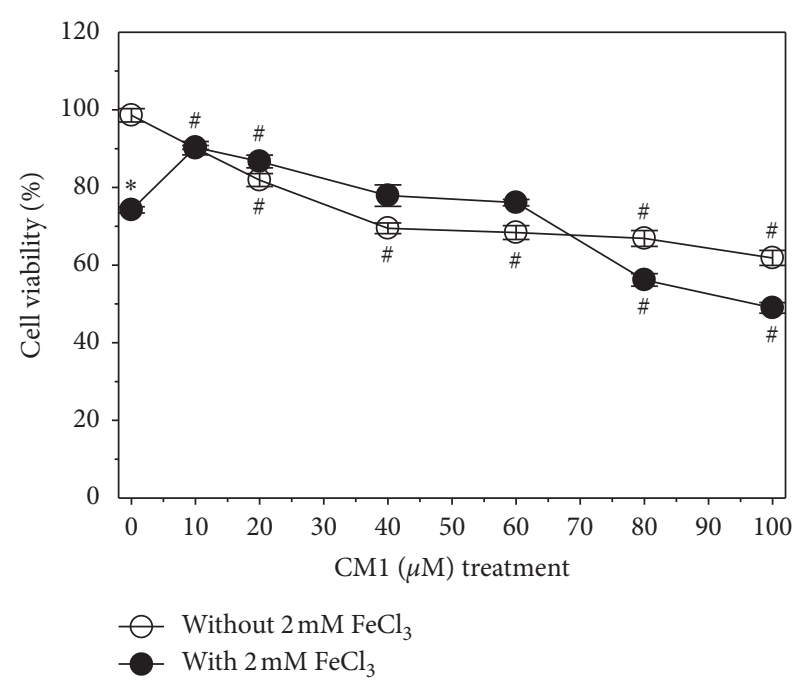

(a)

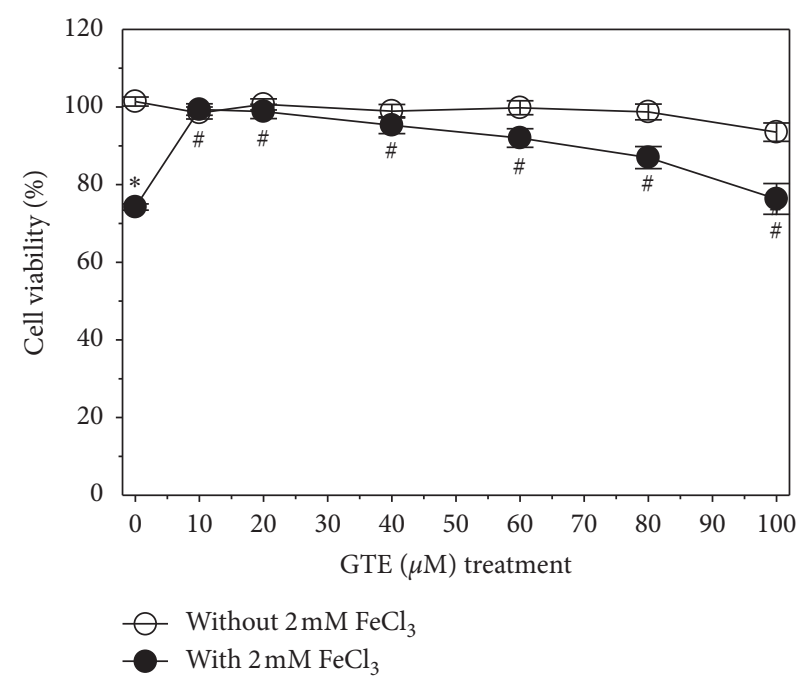

(b)

FIGURE 1: Viability of SH-SY5Y cells after being exposed to treatments with or without $2 \mathrm{mM} \mathrm{FeCl}_{3}$. Cells were then treated with CM1 $(10-100 \mu \mathrm{M})(\mathrm{a})$ and GTE $(10,20,40,60,80$, and $100 \mathrm{mg} / \mathrm{mL}$ equivalent to $5.24,10.5,20.48,31.4,41.9$, and $52.4 \mu \mathrm{M}$ EGCG, respectively) (b) for $24 \mathrm{~h}$. Data obtained from three independent duplicate experiments are expressed as mean \pm SEM values. ${ }^{*} P<0.05$ when compared to the untreated cells without iron loading; ${ }^{\#} P<0.05$ when compared to the cells without treatment.

manner. CM1 at $10 \mu \mathrm{M}$ and GTE in the range of $10-40 \mathrm{mg}$ / $\mathrm{mL}$ (5.2-21 $\mu \mathrm{M}$ EGCG equivalents) were selected for subsequent experiments.

3.2. Effect on Mitochondrial Function. The iron loading of SH-SY5Y cells was found to disrupt mitochondrial function (Figure 2). Interestingly, GTE (10-40 mg/mL) monotherapy lowered the percentage of MMP disruption in a dose-dependent manner, whereas CM1 monotherapy also induced a change in MMP, but not in a dose-dependent manner. Co-treatment of CM1 and GTE did not promote an enhanced MMP disruption when compared to monotherapy. The results suggest that both CM1 and GTE are able to chelate redox active iron in the mitochondrial compartment and exert a protective effect on oxidative neuroblastoma cell damage.

3.3. Effect on Labile Iron Pool. The amount of intracellular LIP is inversely proportional to fluorescence signal assayed using the calcein fluorescence quenching method. The loading of $2 \mathrm{mM} \mathrm{FeCl}_{3}$ resulted in significant iron accumulation in SH-SY5Y cells when compared to healthy cells monotherapy of CM1 $(10-20 \mu \mathrm{M})$ and GTE did not lead to LIP reduction in iron-loaded cells while higher concentrations slightly decreased the LIP levels $(P>0.05)$. Moreover, combined EGCG treatment with $10 \mu \mathrm{M}$ CM1 slightly enhanced the chelation of LIP, while combined GTE treatment with the two chelators tended to increase the degree of chelation when compared to their monotherapies (Figure 3). It is possible that EGCG and other active phytochemicals in GTE, together with CM1, could cooperatively remove LIP in neuroblastoma cells with iron overload.
3.4. Effect on ROS Production. Obviously, the percentage of ROS production was significantly increased in iron-loaded SH-SY5Y cells when compared to healthy cells; however, the level was significantly decreased by $\alpha$-tocopherol $(0.46 \mu \mathrm{M})$ and then used as a reference fat-soluble anti-oxidant (Figure 4). Monotherapy involving EGCG (10-40 $\mu \mathrm{M})$ showed ineffective free-radical scavenging activity; in contrast, CM1 $(10-40 \mu \mathrm{M})$ and GTE $(10-40 \mathrm{mg} / \mathrm{mL})$ displayed effective free-radical scavenging activity in a concentration-dependent manner, in which the $40 \mu \mathrm{M}$ CM1 was found significantly different. In combined therapy, only $40 \mathrm{mg} / \mathrm{mL}$ GTE along with $10 \mu \mathrm{M}$ CM1 resulted in a significant decrease in ROS production while other combinations did not. The results imply that EGCG and other active phytochemicals in GTE together with CM1 could cooperate to scavenge ROS in neuroblastoma cells with iron overload.

3.5. Effect on Lipid-Peroxidation Reaction. Lipid peroxidation, which mostly occurs on membrane phospholipids, is routinely catalyzed by ROS to generate byproducts including 4-hydroxynonenal, isoprostane, and aldehydes (such as malondialdehyde) that can react with TBA and yield pink-colored TBARS. Apparently, $\mathrm{FeCl}_{3}$ loading catalyzed ROS generation and significantly increased TBARS levels in SH-SY5Y cells, while $\alpha$-tocopherol treatment $(0.46 \mu \mathrm{M})$ was effective in significantly lowering the increase of TBARS levels (Figure 5). Treatments with CM1 and GTE also reduced the cellular TBARS levels in which the GTE was more effective. Importantly, a combination treatment of GTE with $10 \mu \mathrm{M}$ CM1 was more effective than GTE monotherapy in decreasing the TBARS levels in a concentration-dependent manner. The results indicated that antioxidants, such as $\alpha$-tocopherol and green tea extract, directly scavenged ROS 

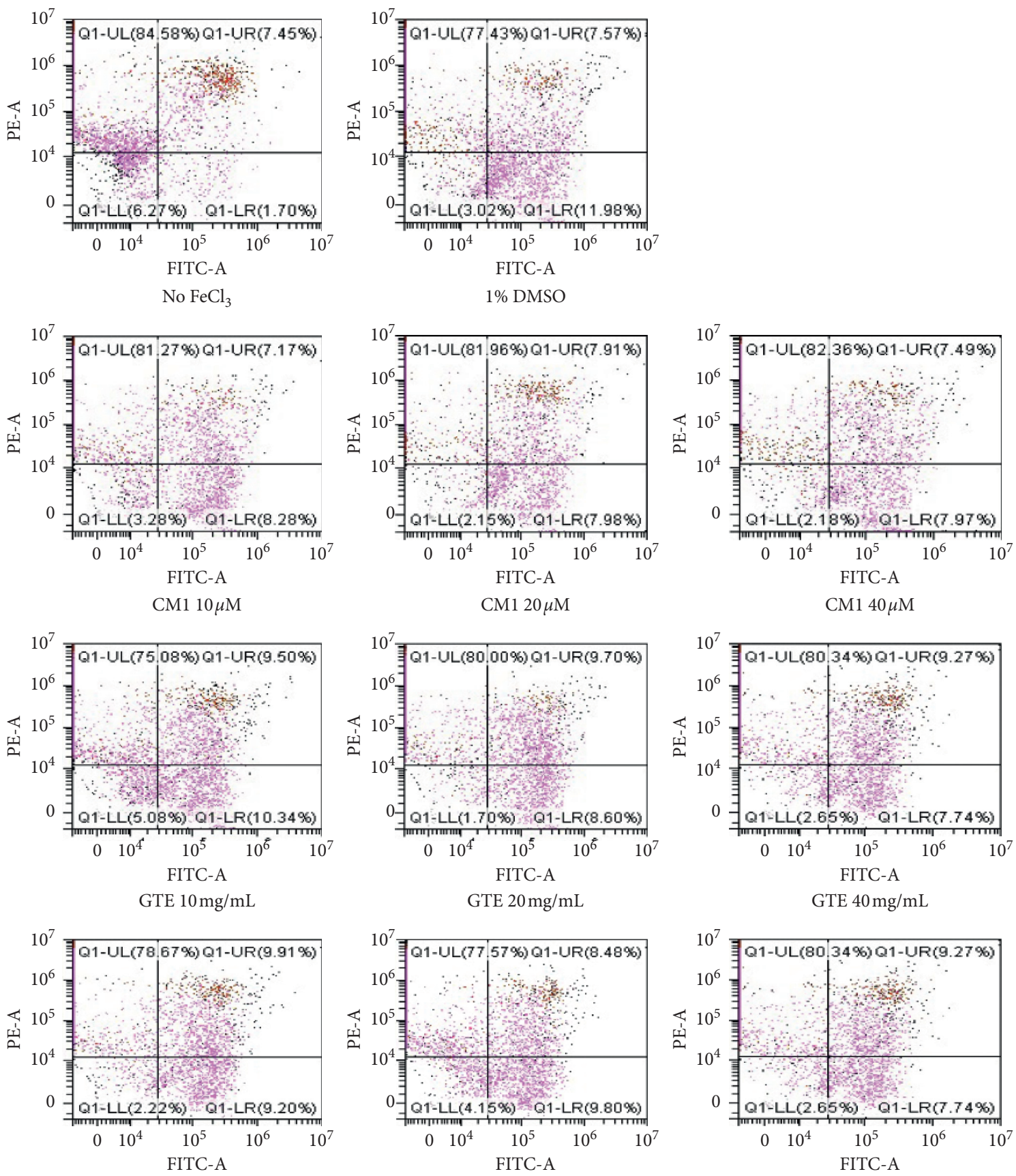

GTE $20 \mathrm{mg} / \mathrm{mL}+\mathrm{CM} 110 \mu \mathrm{M}$

GTE $40 \mathrm{mg} / \mathrm{mL}+\mathrm{CM} 110 \mu \mathrm{M}$

(a)

Figure 2: Continued. 


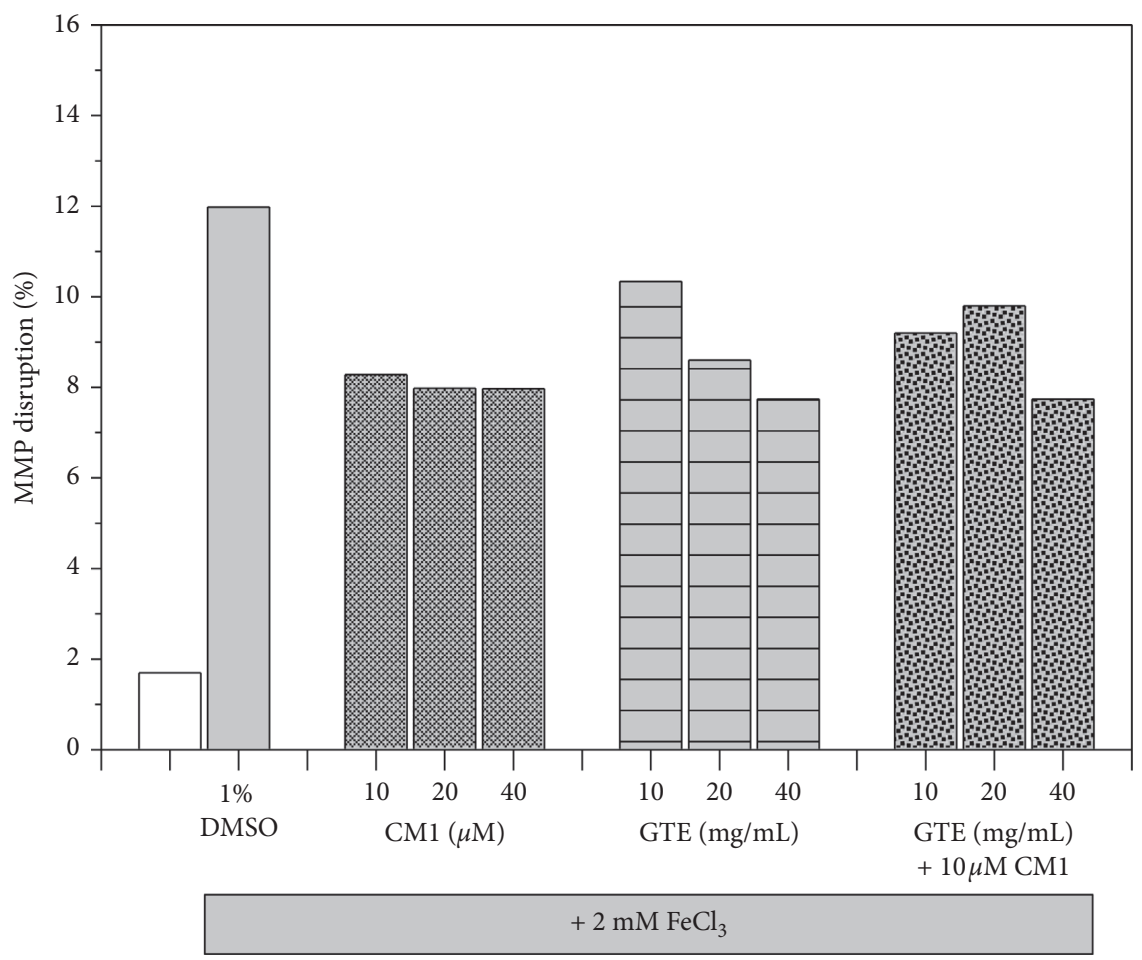

(b)

FIgURE 2: Mitochondrial membrane disruption in SH-SY5Y cells after being exposed to treatments with or without $2 \mathrm{mM} \mathrm{FeCl}_{3}$. Cells were then treated with $1 \%$ DMSO, CM1 (10-40 $\mu \mathrm{M})$, GTE $(10,20$, and $40 \mathrm{mg} / \mathrm{mL}$ equivalent to $5.24,10.48$, and $20.96 \mu \mathrm{M}$ EGCG, respectively) and a combination of CM1 and GTE for $24 \mathrm{~h}$. Data are expressed as dot-plot graphs (a) and histogram of triplicate experiments (b).

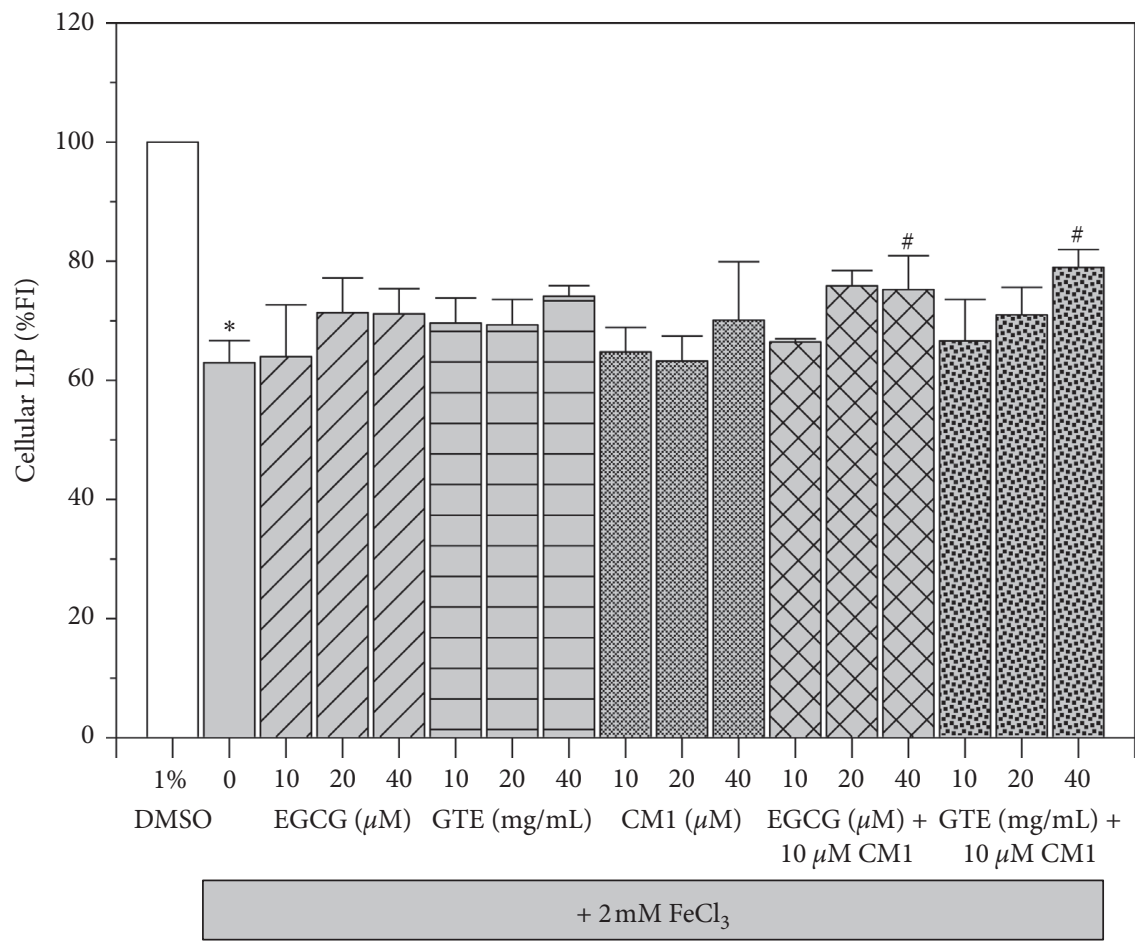

FIGURE 3: Levels of LIP in SH-SY5Y cells with iron loading condition. SH-SY5Y cells were being exposed with or without 2 mM FeCl 3 . After that, the cells were then treated with 1\% DMSO, CM1 (10-40 $\mu \mathrm{M})$, EGCG (10-40 $\mu \mathrm{M})$, GTE (10, 20, and $40 \mathrm{mg} / \mathrm{mL}$ equivalent to $5.24,10.48$, and $20.96 \mu \mathrm{M}$ EGCG, respectively), and combinations for $24 \mathrm{~h}$. Data obtained from three independent duplicate experiments are expressed as mean \pm SEM values. ${ }^{*} P<0.05$ when compared to the untreated cells without iron loading; ${ }^{\#} P<0.05$ when compared to the iron-loaded cells treated with $1 \%$ DMSO. 


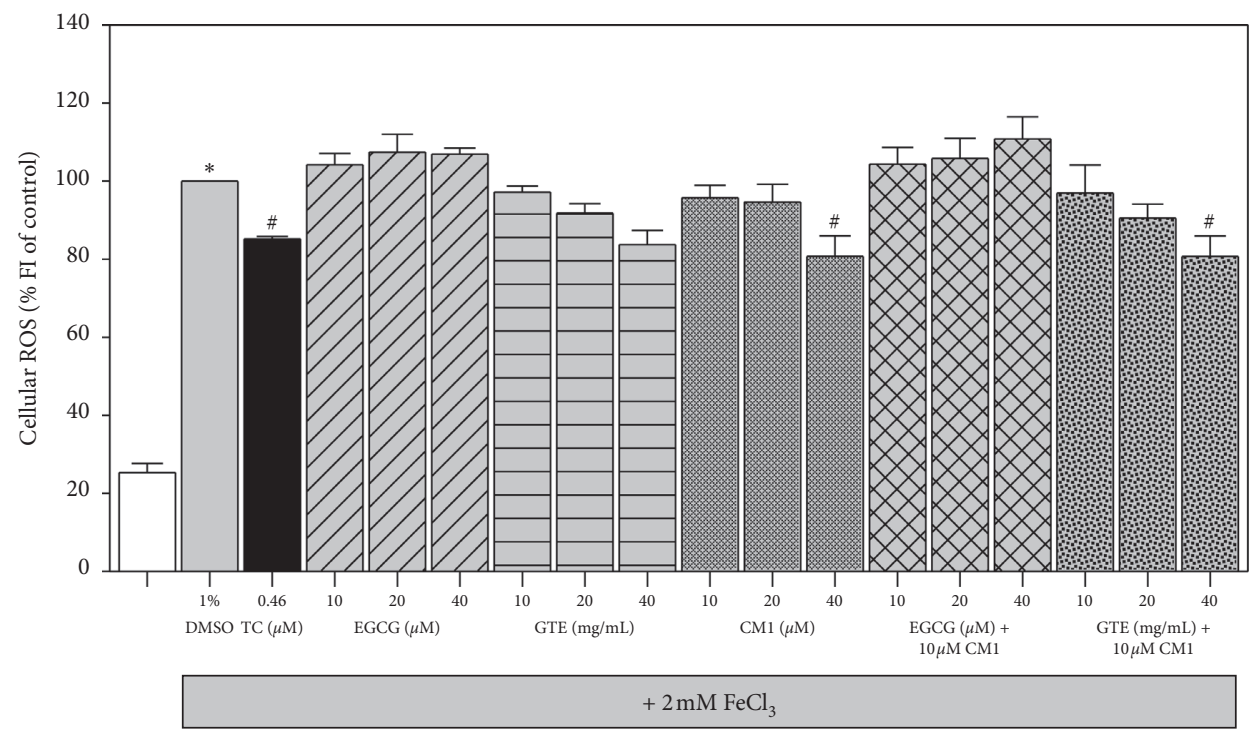

FIGURE 4: Levels of ROS in SH-SY5Y cells after being exposed to treatments with or without $2 \mathrm{mM} \mathrm{FeCl}_{3}$. Cells were then treated with $1 \%$ DMSO, TC $(0.46 \mu \mathrm{M})$, CM1 $(10-40 \mu \mathrm{M})$, EGCG $(10-40 \mu \mathrm{M})$, GTE $(10,20$, and $40 \mathrm{mg} / \mathrm{mL}$ equivalent to 5.24, 10.48, and 20.96 $\mu \mathrm{M}$ EGCG, respectively), and combinations for $24 \mathrm{~h}$. Data obtained from three independent duplicate experiments are expressed as mean \pm SEM values. ${ }^{*} P<0.05$ when compared to the untreated cells without iron loading; ${ }^{\#} P<0.05$ when compared to the iron-loaded cells treated with $1 \%$ DMSO.

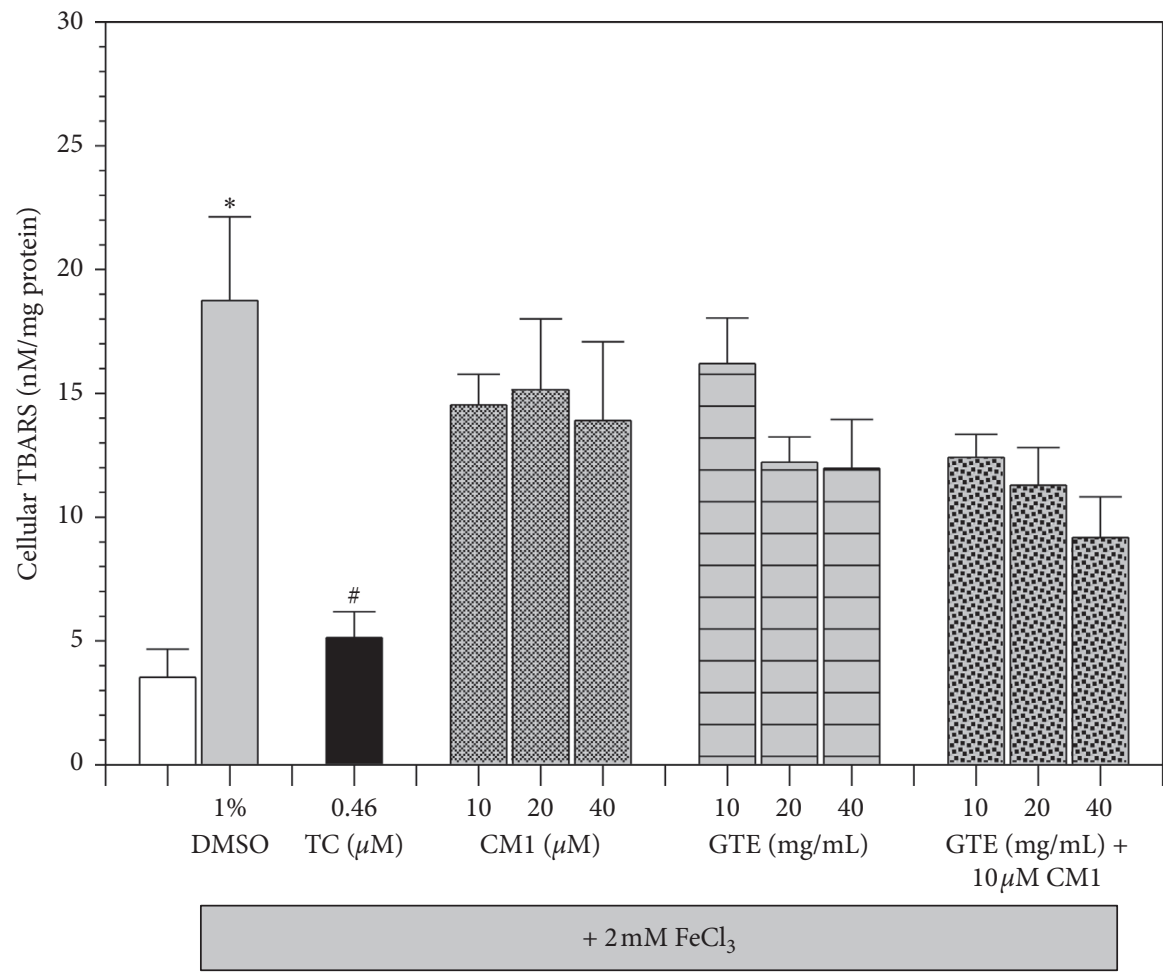

FIGURE 5: Levels of TBARS in SH-SY5Y cells after being exposed to treatments with or without $2 \mathrm{mM} \mathrm{FeCl}_{3}$. Cells were treated with $1 \%$ DMSO, TC $(0.46 \mu \mathrm{M}), \mathrm{CM} 1(10-40 \mu \mathrm{M})$, GTE $(10,20$, and $40 \mathrm{mg} / \mathrm{mL}$ equivalent to $5.24,10.48$, and $20.96 \mu \mathrm{M}$ EGCG, respectively), and a combination of GTE and CM1 for $24 \mathrm{~h}$. Data obtained from three independent duplicate experiments are expressed as mean \pm SEM values. ${ }^{*} P<0.05$ when compared to the untreated cells without iron loading; ${ }^{\#} P<0.05$ when compared to the iron-loaded cells treated with $1 \%$ DMSO. 
and subsequently prevented lipid-peroxidation reactions in neuroblastoma cells. Thus, they were found to be more effective in this manner than other iron chelators such as CM1.

\section{Discussion}

Iron is a crucial trace element required for many important brain functions including energy metabolism, synaptic plasticity, myelination, and synthesis of neurotransmitters $[33,34]$. Many neurodegenerative diseases have been associated with the disruption of brain iron homeostasis resulting in an accumulation of brain iron and the provoking of chronic neuroinflammation $[4,35,36]$. Importantly, a redox-active iron can generate ROS via a Fenton reaction, which is one of the mechanisms believed to play an important role in the pathogenesis of Alzheimer's disease and Parkinson's disease [37-40]. Indeed, the levels of generated ROS are significantly higher in the brains of Alzheimer's patients when compared to healthy control brains [41, 42]. Furthermore, many studies have reported that oxidative stress promotes neurotoxic oligomerization of $\mathrm{A} \beta$ peptides and tau tangles $[43,44]$. ROS also activated microglia to release pro-inflammatory cytokines that are known to cause chronic inflammation $[45,46]$. On the other hand, patients with Parkinson's disease have been observed with high total iron concentrations in the substantia nigra that might be associated with increased divalent metal iron transporter 1 activity or decreased ferroxidase activity of ceruloplasmin, potentially both of which would increase total intracellular iron as has been reported in patients and animal models $[38,47,48]$. The mechanism of iron-induced neuronal cell death has been reported by Bautista and colleagues [49]. They found increases of extracellular signal-regulated kinase (ERK) and protein kinase B (PKB also known as Akt) activities and a reduction of dual specificity tyrosine-phos phorylation-regulated kinase $1 \mathrm{~B}$ (DyrK1B) after $\mathrm{FeCl}_{3}$ treatment. Furthermore, they also recorded activated transcription factors, such as c-Jun and phosphor-Smad1/5, suggesting that the presence of a high concentration of iron could increase the vulnerability of neurons to oxidative stress.

Since high iron accumulation is a cause of neuronal cell death, iron chelation might be considered a useful form of therapy and has therefore received a significant amount of attention. Previous studies have reported on the neuroprotective effect of iron chelators such as DFP, deferoxamine, and others [50-53]. However, these chemical drugs may exhibit adverse effects suggesting that non-toxic products are required. Our lead compound, CM1, is a synthetic bidentate chelator that is more lipophilic than DFP and can bind the iron efficiently [17]. Interestingly, the chelator is able to chelate NTBI in thalassemic serum, but is not toxic to peripheral blood mononuclear cells, hepatocytes, and myocytes in vitro [20]. Due to the high cost of chemical drugs, we are increasingly interested in alternative therapies that employ natural products. Several studies have demonstrated that green tea has neuroprotective functions, as well as non-toxic and positive synergistic effects. Green tea contains high amounts of polyphenolic catechins including EGCG, epigallocatechin, epicatechin, and epicatechin-3-gallate [54, 55]. Many studies have shown that EGCG exhibits a range of anti-oxidant, anti-inflammatory, anti-microbial, anti-cancer, and neuroprotective properties [56-58]. Interestingly, EGCG can cross the blood brain barrier and display its neuroprotective effect $[21,59]$. In order to investigate the neuroprotective effect of an oral iron chelator, CM1 in combination with GTE under iron-over loaded conditions in neuroblastoma cells, such as SH-SY5Y cells, was prepared and its protective effect was assessed against iron-induced oxidative stress. The results demonstrate that high concentrations of CM1 were toxic to the cells because iron depletion can affect many important processes of the cells. In combination treatments, we combined a nontoxic dose of CM1 with GTE at various concentrations. It was found that co-treatment of CM1 and GTE exhibited greater activities by saving cell viability and could decrease the levels of labile iron pool, ROS, and lipid-peroxidation products presented as TBARS. The findings suggest that CM1 and green tea extract exhibit a synergistic action to protect the neuroblastoma cells from iron-induced oxidative stress by chelating excessive iron and reducing ROS via antioxidant properties. However, studies involving both animals and humans require further elucidation for applications in alternative medicine.

\section{Conclusion}

A combination of CM1 and green tea extract exhibited enhanced neuroprotective action against iron-induced oxidative stress in neuroblastoma cells by improving cell viability and mitochondrial function, and reducing levels of labile iron pool, reactive oxygen species, and lipid-peroxidation products.

\section{Abbreviations}

ANOVA: One-way analysis of variance

CA-AM: Calcein acetoxymethyl

CM1: 1-(N-acetyl-6-aminohexyl)-3-hydroxy-2-me thylpyridin-4-one

DCFH-DA: $2^{\prime}, 7^{\prime}$-Dichlorodihydrofluorescein diacetate

DFP: Deferiprone

DMEM: Dulbecco's Modified Eagle Medium

DMSO: Dimethyl sulfoxide

DyrK1B: Dual specificity tyrosine-phosphorylation-reg ulated kinase $1 \mathrm{~B}$

EGCG: $\quad$ Epigallocatechin-3-gallate

ERK: $\quad$ Extracellular signal-regulated kinase

FBS: $\quad$ Fetal bovine serum

FI: $\quad$ Fluorescence intensity

GTE: Green tea extract

LIP: $\quad$ Labile iron pool

MDA: $\quad$ Malondialdehyde

MTT: 3-(4,5-Dimethyl-2-thiazolyl)-2,5-diphenyl-2- $H$-te trazolium bromide

MMP: $\quad$ Mitochondrial membrane potential

OD: $\quad$ Optical density

PBS: $\quad$ Phosphate-buffered saline 
PKB: $\quad$ Protein kinase B

ROS: $\quad$ Reactive oxygen species

SEM: $\quad$ Standard error of mean

TBA: Thiobarbituric acid

TBARS: Thiobarbituric acid-reactive substances

TMP: $\quad$ 1,1,3,3-Tetramethoxypropane

UV-VIS: Ultraviolet-visible.

\section{Data Availability}

The data used to support the findings of this study are available within the article and from the corresponding author upon request.

\section{Conflicts of Interest}

All the authors involved have approved of the submitted manuscript and confirm that they hold no conflicts of interest.

\section{Authors' Contributions}

NC acquired funding, conceptualized the investigations, quantified cellular TBARS, and wrote a draft of the manuscript; KK supplied essential chemicals and prepared SHSY5Y cell culture; NP conducted experiments for cell toxicity, labile iron, and cellular ROS assays; AP measured mitochondrial membrane potential in SH-SY5Y cells; SS supplied GTE and CM1, discussed the results, and corresponded with the journal's editor and reviewers.

\section{Acknowledgments}

The authors gratefully acknowledge the financial support provided by the National Research Council of Thailand and Mae Fah Luang University (No.61211320015). The authors would like to thank the Department of Biochemistry, Faculty of Medicine, Chiang Mai University, and the School of Medicine, Mae Fah Luang University, for providing the necessary facilities.

\section{References}

[1] G. Papanikolaou and K. Pantopoulos, "Iron metabolism and toxicity," Toxicology and Applied Pharmacology, vol. 202, no. 2, pp. 199-211, 2005.

[2] N. Bresgen and P. Eckl, "Oxidative stress and the homeodynamics of iron metabolism," Biomolecules, vol. 5, no. 2, pp. 808-847, 2015.

[3] J. Emerit, C. Beaumont, and F. Trivin, "Iron metabolism, free radicals, and oxidative injury," Biomedicine \& Pharmacotherapy, vol. 55, no. 6, pp. 333-339, 2001.

[4] A. Carocci, A. Catalano, M. S. Sinicropi, and G. Genchi, "Oxidative stress and neurodegeneration: the involvement of iron," Biometals, vol. 31, no. 5, pp. 715-735, 2018.

[5] M. Kruszewski, "Labile iron pool: the main determinant of cellular response to oxidative stress," Mutation Research/ Fundamental and Molecular Mechanisms of Mutagenesis, vol. 531, no. 1-2, pp. 81-92, 2003.
[6] S. Apostolakis and A.-M. Kypraiou, "Iron in neurodegenerative disorders: being in the wrong place at the wrong time?" Reviews in the Neurosciences, vol. 28, no. 8, pp. 893-911, 2017.

[7] K. Yoshida, "[Iron accumulation and neurodegenerative diseases]," Nihon Rinsho, vol. 74, no. 7, pp. 1161-1167, 2016.

[8] A. A. Belaidi and A. I. Bush, "Iron neurochemistry in Alzheimer's disease and Parkinson's disease: targets for therapeutics," Journal of Neurochemistry, vol. 139, no. Suppl 1, pp. 179-197, 2016.

[9] H. Jiang, J. Wang, J. Rogers, and J. Xie, "Brain iron metabolism dysfunction in Parkinson's disease," Molecular Neurobiology, vol. 54, no. 4, pp. 3078-3101, 2017.

[10] A. Prakash, G. K. Dhaliwal, P. Kumar, and A. B. A. Majeed, "Brain biometals and Alzheimer's disease-boon or bane?" International Journal of Neuroscience, vol. 127, no. 2, pp. 99-108, 2017.

[11] P. Aguirre, O. García-Beltrán, V. Tapia, Y. Muñoz, B. K. Cassels, and M. T. Núñez, "Neuroprotective effect of a new 7,8-dihydroxycoumarin-based $\mathrm{Fe} 2+/ \mathrm{Cu} 2+$ Chelator in cell and animal models of Parkinson's disease," ACS Chemical Neuroscience, vol. 8, no. 1, pp. 178-185, 2016.

[12] D. Blat, L. Weiner, M. B. H. Youdim, and M. Fridkin, "A Novel iron-chelating derivative of the neuroprotective peptide NAPVSIPQ shows superior antioxidant and antineurodegenerative capabilities," Journal of Medicinal Chemistry, vol. 51, no. 1, pp. 126-134, 2008.

[13] F. Molina-Holgado, A. Gaeta, P. T. Francis, R. J. Williams, and R. C. Hider, "Neuroprotective actions of deferiprone in cultured cortical neurones and SHSY-5Y cells," Journal of Neurochemistry, vol. 105, no. 6, pp. 2466-2476, 2008.

[14] Y. Levites, M. B. H. Youdim, G. Maor, and S. Mandel, "Attenuation of 6-hydroxydopamine (6-OHDA)-induced nuclear factor-kappaB (NF- $\kappa \mathrm{B})$ activation and cell death by tea extracts in neuronal cultures11Abbreviations: BT, black tea; EMSA, electromobility shift assay; EGCG, (-)-Epigallocatechin-3-gallate; GT, green tea; NB SH-SY5Y cells, human neuroblastoma SHSY5Y cells; 6-OHDA, 6-hydroxydopamine; IL, Interleukin; LDH, lactate dehydrogenase; MPTP, N-methyl-4-phenyl-1,2,3,6-tet rahydropyridine; NF- $\kappa \mathrm{B}$, nuclear factor- $\kappa \mathrm{B}$; OS, oxidative stress; $\mathrm{PD}$, Parkinson's disease; ROS, reactive oxygen species; SNPC, substantia nigra pars compacta; TBARS, thiobarbituric acid reactive substances," Biochemical Pharmacology, vol. 63, no. 1, pp. 21-29, 2002.

[15] L. Reznichenko, T. Amit, H. Zheng et al., "Reduction of ironregulated amyloid precursor protein and $\beta$-amyloid peptide by (-)-epigallocatechin-3-gallate in cell cultures: implications for iron chelation in Alzheimer's disease," Journal of Neurochemistry, vol. 97, no. 2, pp. 527-536, 2006.

[16] S. Upanan, K. Pangjit, C. Uthaipibull, S. Fucharoen, A. T. McKie, and S. Srichairatanakool, "Combined treatment of 3-hydroxypyridine-4-one derivatives and green tea extract to induce hepcidin expression in iron-overloaded $\beta$-thalassemic mice," Asian Pacific Journal of Tropical Biomedicine, vol. 5, no. 12, pp. 1010-1017, 2015.

[17] K. Pangjit, R. Banjerdpongchai, C. Phisalaphong et al., "Characterisation of a novel oral iron chelator: 1-(N-Acetyl-6-a minohexyl)-3-hydroxy-2-methylpyridin-4-one," Journal of Pharmacy and Pharmacology, vol. 67, no. 5, pp. 703-713, 2015.

[18] S. Srichairatanakool, K. Pangjit, C. Phisalaphong, and S. Fucharoen, "Evaluation of a novel oral iron chelator 1-(N-acetyl-6-aminohexyl)-3-hydroxypyridin-4-one (CM1) for treatment of iron overload in mice," Advances in Bioscience and Biotechnology, vol. 4, no. 2, pp. 153-163, 2013. 
[19] N. Chansiw, K. Pangjit, C. Phisalaphong et al., "Effect of a novel oral active iron chelator: 1-(N-acetyl-6-aminohexyl)-3-hy droxy-2-methylpyridin-4-one (CM1) in iron-overloaded and non-overloaded mice," Asian Pacific Journal of Tropical Medicine, vol. 7, pp. S155-S161, 2014.

[20] K. Pangjit, R. Banjerdpongchai, C. Phisalaphong, S. Fucharoen, and S. Srichairatanakool, "Efficacy of 1-(N-acetyl-6-aminohexyl)-3-hydroxypyridin-4-one (CM1) in treatment of iron-loaded hepatocyte cultures," Advances in Bioscience and Biotechnology, vol. 3, no. 7, pp. 1060-1067, 2012.

[21] N. A. Singh, A. K. Mandal, and Z. A. Khan, "Potential neuroprotective properties of epigallocatechin-3-gallate (EGCG)," Nutrition Journal, vol. 15, no. 1, p. 60, 2016.

[22] S. Khokhar and S. G. M. Magnusdottir, "Total phenol, catechin, and caffeine contents of teas commonly consumed in the United Kingdom," Journal of Agricultural and Food Chemistry, vol. 50, no. 3, pp. 565-570, 2002.

[23] J. Zhao, L. Xu, Q. Liang et al., "Metal chelator EGCG attenuates $\mathrm{Fe}(\mathrm{III})$-induced conformational transition of $\alpha$-synuclein and protects AS-PC12 cells against Fe(III)-induced death," Journal of Neurochemistry, vol. 143, no. 1, pp. 136-146, 2017.

[24] O. Weinreb, T. Amit, and M. B. H. Youdim, "The application of proteomics for studying the neurorescue activity of the polyphenol (-)-epigallocatechin-3-gallate," Archives of Biochemistry and Biophysics, vol. 476, no. 2, pp. 152-160, 2008.

[25] T. Saewong, S. Ounjaijean, Y. Mundee et al., "Effects of green tea on iron accumulation and oxidative stress in livers of ironchallenged thalassemic mice," Medicinal Chemistry, vol. 6, no. 2, pp. 57-64, 2010.

[26] H. Lu, J. Chen, H. Huang et al., "Iron modulates the activity of monoamine oxidase B in SH-SY5Y cells," Biometals, vol. 30, no. 4, pp. 599-607, 2017.

[27] S. Basu, M. L. Mohan, X. Luo, B. Kundu, Q. Kong, and N. Singh, "Modulation of proteinase K-resistant prion protein in cells and infectious brain homogenate by redox iron: implications for prion replication and disease pathogenesis," Molecular Biology of the Cell, vol. 18, no. 9, pp. 3302-3312, 2007.

[28] R. Quiroz-Baez, E. Rojas, and C. Arias, "Oxidative stress promotes JNK-dependent amyloidogenic processing of normally expressed human APP by differential modification of $\alpha$-, $\beta$ - and $\gamma$-secretase expression," Neurochemistry International, vol. 55, no. 7, pp. 662-670, 2009.

[29] D. M. Morgan, "Tetrazolium (MTT) assay for cellular viability and activity," Methods in Molecular Biology (Clifton, N.J.), vol. 79, pp. 179-183, 1998.

[30] T. Menke, G. Gille, F. Reber et al., "Coenzyme Q10 reduces the toxicity of rotenone in neuronal cultures by preserving the mitochondrial membrane potential," Biofactors, vol. 18, no. 14, pp. 65-72, 2003.

[31] B. P. Espósito, S. Epsztejn, W. Breuer, and Z. I. Cabantchik, "A review of fluorescence methods for assessing labile iron in cells and biological fluids," Analytical Biochemistry, vol. 304, no. 1, pp. 1-18, 2002.

[32] A. Aranda, L. Sequedo, L. Tolosa et al., "Dichloro-dihydrofluorescein diacetate (DCFH-DA) assay: a quantitative method for oxidative stress assessment of nanoparticletreated cells," Toxicology in Vitro: An International Journal Published in Association with BIBRA, vol. 27, no. 2, pp. 954-963, 2013.

[33] S. Mandel, E. Grunblatt, and P. Riederer, "Iron in brain function and neurodegenerative disorders," Editorial Journal of Neural Transmission (Vienna), vol. 118, no. 3, pp. 299-300, 2011.

[34] M. B. Youdim, "Iron deficiency effects on brain function," Public Health Reviews, vol. 28, no. 1-4, pp. 83-88, 2000.

[35] R. J. Ward, D. T. Dexter, and R. R. Crichton, "Ageing neuroinflammation and neurodegeneration," Frontiers in Bioscience, vol. 7, no. 1, pp. 189-204, 2015.

[36] R. J. Ward, F. A. Zucca, J. H. Duyn, R. R. Crichton, and L. Zecca, "The role of iron in brain ageing and neurodegenerative disorders," The Lancet Neurology, vol. 13, no. 10, pp. 1045-1060, 2014.

[37] L. Du, Z. Zhao, A. Cui et al., "Increased iron deposition on brain quantitative susceptibility mapping correlates with decreased cognitive function in Alzheimer's disease," ACS Chemical Neuroscience, vol. 9, no. 7, pp. 1849-1857, 2018.

[38] B. Pesch, S. Casjens, D. Woitalla et al., "Impairment of motor function correlates with neurometabolite and brain iron alterations in Parkinson's disease," Cells, vol. 8, no. 2, 2019.

[39] P. Matak, A. Matak, S. Moustafa et al., "Disrupted iron homeostasis causes dopaminergic neurodegeneration in mice," Proceedings of the National Academy of Sciences, vol. 113, no. 13, pp. 3428-3435, 2016.

[40] E. Madsen and J. D. Gitlin, "Copper and iron disorders of the brain," Annual Review of Neuroscience, vol. 30, no. 1, pp. 317-337, 2007.

[41] T. Skjørringe, L. B. Møller, and T. Moos, "Impairment of interrelated iron- and copper homeostatic mechanisms in brain contributes to the pathogenesis of neurodegenerative disorders," Frontiers in Pharmacology, vol. 3, p. 169, 2012.

[42] X.-H. Dong, W.-J. Gao, W.-N. Kong et al., "Neuroprotective effect of the active components of three Chinese herbs on brain iron load in a mouse model of Alzheimer's disease," Experimental and Therapeutic Medicine, vol. 9, no. 4, pp. 1319-1327, 2015.

[43] D. Schubert and M. Chevion, "The role of iron in beta amyloid toxicity," Biochemical and Biophysical Research Communications, vol. 216, no. 2, pp. 702-707, 1995.

[44] F. Kuperstein and E. Yavin, "Pro-apoptotic signaling in neuronal cells following iron and amyloid beta peptide neurotoxicity," Journal of Neurochemistry, vol. 86, no. 1, pp. 114-125, 2003.

[45] I. C. Nnah and M. Wessling-Resnick, "Brain iron homeostasis: a focus on microglial iron," Pharmaceuticals (Basel), vol. 11, no. 4, 2018.

[46] T. J. Huat, J. Camats-Perna, E. A. Newcombe, N. Valmas, M. Kitazawa, and R. Medeiros, "Metal toxicity links to Alzheimer's disease and neuroinflammation," Journal of Molecular Biology, vol. 43, no. 9, pp. 1843-1868, 2019.

[47] X. Guan, Y. Zhang, H. Wei et al., "Iron-related nigral degeneration influences functional topology mediated by striatal dysfunction in Parkinson's disease," Neurobiology of Aging, vol. 75, pp. 83-97, 2019.

[48] G. Bjorklund, V. Stejskal, M. A. Urbina, M. Dadar, S. Chirumbolo, and J. Mutter, "Metals and Parkinson's disease: mechanisms and biochemical processes," Current $\mathrm{Me}$ dicinal Chemistry, vol. 25, no. 19, pp. 2198-2214, 2018.

[49] E. Bautista, P. Vergara, and J. Segovia, "Iron-induced oxidative stress activates AKT and ERK1/2 and decreases Dyrk1B and PRMT1 in neuroblastoma SH-SY5Y cells," Journal of Trace Elements in Medicine and Biology, vol. 34, pp. 62-69, 2016.

[50] Y. Zhang and M.-L. He, "Deferoxamine enhances alternative activation of microglia and inhibits amyloid beta deposits in APP/PS1 mice," Brain Research, vol. 1677, pp. 86-92, 2017. 
[51] E. Carboni, L. Tatenhorst, L. Tonges et al., "Deferiprone rescues behavioral deficits induced by mild iron exposure in a mouse model of alpha-synuclein aggregation," NeuroMolecular Medicine, vol. 19, no. 2-3, pp. 309-321, 2017.

[52] Y. Tian, Y. He, W. Song, E. Zhang, and X. Xia, "Neuroprotective effect of deferoxamine on N-methyl-d-aspartate-induced excitotoxicity in RGC-5 cells," Acta Biochimica et Biophysica Sinica, vol. 49, no. 9, pp. 827-834, 2017.

[53] M. P. Gotsbacher, T. J. Telfer, P. K. Witting, K. L. Double, D. I. Finkelstein, and R. Codd, "Analogues of desferrioxamine $\mathrm{B}$ designed to attenuate iron-mediated neurodegeneration: synthesis, characterisation and activity in the MPTP-mouse model of Parkinson's disease," Metallomics, vol. 9, no. 7, pp. 852-864, 2017.

[54] L. Chakrawarti, R. Agrawal, S. Dang, S. Gupta, and R. Gabrani, "Therapeutic effects of EGCG: a patent review," Expert Opinion on Therapeutic Patents, vol. 26, no. 8, pp. 907-916, 2016.

[55] L.-C. Lin, M.-N. Wang, T.-Y. Tseng, J. S. Sung, and T.-H. Tsai, "Pharmacokinetics of (-)-Epigallocatechin-3-gallate in conscious and freely moving rats and its brain regional distribution," Journal of Agricultural and Food Chemistry, vol. 55, no. 4, pp. 1517-1524, 2007.

[56] M. I. Prasanth, B. S. Sivamaruthi, C. Chaiyasut, and T. Tencomnao, "A Review of the role of green tea (Camellia sinensis) in antiphotoaging, stress resistance, neuroprotection, and autophagy," Nutrients, vol. 11, no. 2, 2019.

[57] N. Khan, F. Afaq, M. Saleem, N. Ahmad, and H. Mukhtar, "Targeting multiple signaling pathways by green tea polyphenol (-)-Epigallocatechin-3-Gallate," Cancer Research, vol. 66, no. 5, pp. 2500-2505, 2006.

[58] K. Unno, F. Takabayashi, H. Yoshida et al., "Daily consumption of green tea catechin delays memory regression in aged mice," Biogerontology, vol. 8, no. 2, pp. 89-95, 2007.

[59] L. Xicota, J. Rodriguez-Morato, M. Dierssen, and R. de la Torre, "Potential role of (-)-epigallocatechin-3-gallate (EGCG) in the secondary prevention of Alzheimer disease," Current Drug Targets, vol. 18, no. 2, pp. 174-195, 2017. 